\title{
ESTUDO DE SIMULAÇÕES DE MICROCLIMAS EM CASAS DE VEGETAÇÃO VISANDO À ACLIMATAÇÃO DE MUDAS MICROPROPAGADAS DE BANANEIRA CV GRANDE NAINE ${ }^{1}$
}

\author{
CIRO SCARANARI ${ }^{2}$, PAULO ADEMAR MARTINS LEAL ${ }^{3}$, GIAMPAOLO QUEIROZ PELLEGRINO ${ }^{4}$
}

RESUMO- Em processos de aclimatação, o controle ambiental assume papel de vital importância, pois, ainda na condição in vitro, as plantas não operam eficientemente a absorção de luz, água e nutrientes. Devem, portanto, ser submetidas a ambientes controlados sob condições favoráveis de luminosidade, temperatura (ao redor de $28^{\circ} \mathrm{C}$, com mínimas a $18^{\circ} \mathrm{C}$ e máximas a $34^{\circ} \mathrm{C}$ ) e umidade relativa (acima de 75\%). Para tanto, foram construídos 5 mini-túneis com temperatura e umidade relativa controladas. No controle da temperatura, usaram-se resfriadores evaporativos do tipo ventilador-meio poroso, $28 / 25^{\circ} \mathrm{C}$. No controle da umidade relativa, usou-se nebulização durante o dia a 75\% sob intermitência de $6 \mathrm{~s}$ a cada 40s. Para o monitoramento da temperatura e umidade relativa, foram instalados 3 psicrômetros aspirados em cada casa de vegetação, ligados a sistema programado para leituras diárias com partição de 60s. Os resultados indicam controle satisfatório nos ambientes, oferecendo condições favoráveis para as plantas de bananeira sob o $2^{\circ}$ estágio de aclimatação, embora tenham sido observadas diferenças significativas entre eles. Para o estudo da luminosidade, sob filme plástico transparente PEBD de $100 \mu \mathrm{m}$, foram utilizadas telas com média de sombreamento na faixa RFA (400 a 700nm) de 69,92\%, $50,73 \%, 29,73 \%$ e $57,77 \%$, sendo as 3 primeiras de cor vermelha (com picos na faixa de $580 \mathrm{~nm}$ e redução abrupta a partir daí), e a última de cor preta (comportamento linear), respectivamente. $\mathrm{O} 5^{\circ}$ ambiente contou apenas com o filme, apresentando 12,74\% de interceptação da radiação solar. Esses valores foram obtidos a partir de amostras pareadas, tela e filme para os 4 primeiros ambientes e apenas o filme para o último, utilizando-se de espectro-radiômetro programado para a faixa de 400 a $1.100 \mathrm{~nm}$, com resolução espectral de $2 \mathrm{~nm}$. Dentro e fora de cada ambiente, obtiveram-se dados de irradiâncias RFA e global, por meio de sensores fotovoltaicos de silício, por volta das $9 \mathrm{~h}, 12 \mathrm{~h}$ e $15 \mathrm{~h}$, sob condições de céu claro e encoberto, durante o verão de 2004/05 e inverno de 2005. As malhas vermelhas apresentam transmitâncias diferenciadas ao longo do espectro da radiação fotossinteticamente ativa, constituindo-se assim em interessantes materiais para os pretendidos estudos sobre aclimatação. Resultados mostram maiores reduções na faixa RFA para as telas vermelhas, independentes do horário, insolação e estação do ano, concordantes com aqueles obtidos por espectro-radiômetro.

Termos para indexação: Musa sp., ambiência, mudas, sombreamento.

\section{SIMULATIONS OF MICROCLIMATE IN GREENHOUSES AIMING THE ACCLIMATIZATION OF MICROPROPAGATED SEEDLINGS OF BANANA CV. GRANDE NAINE}

\begin{abstract}
In acclimatization processes, the environment control takes over a part of vital importance, since in in vitro condition banana seedlings do not efficiently operate the absorption of light, water and nutrients. Therefore, they should be submitted to controlled environments under feasible conditions of luminosity, temperature (around $28^{\circ} \mathrm{C}$, with minimum of $18^{\circ} \mathrm{C}$ and maximum of $34^{\circ} \mathrm{C}$ ), and relative humidity above $75 \%$. For this purpose, it was installed five mini tunnels with controlled temperature and relative humidity. For the control of temperature it was used pad-fan evaporative coolers at $28 / 25^{\circ} \mathrm{C}$. For the control of relative humidity it was used fogging during the day at $75 \%$ under intermittence of $6 \mathrm{~s}$ at each $40 \mathrm{~s}$. For temperature and relative humidity monitoring, it was installed three aspirate psychrometers in each mini tunnel connected to a data logger for daily acquisition every 60s. Temperature and relative air humidity were adequate for plants development, however significant differences were observed between the different environment conditions. For luminosity study, under transparent plastic film (low density polyethylene) of 100 $\mu \mathrm{m}$ thickness, it was used four meshes with average shading in the PAR spectrum band (400 to 700nm) of 69.92\%, 50.73\%, 29.73\%, and 57.77\%, being the first three in red color (with top level at $580 \mathrm{~nm}$, and abrupt reduction after that), the fourth mesh was black (linear behavior). The fifth tunnel had only transparent plastic film, showing $12.74 \%$ of solar radiation interception. These values were obtained from paired samples (mesh and plastic film) for the first four tunnels, and only the transparent plastic film for the last, using a spectral radiometer (400 to $1100 \mathrm{~nm}$ ), with spectral resolution of $2 \mathrm{~nm}$. Inside and outside of each environment it was obtained global and PAR irradiance by using calibrated photovoltaic sensors at 9:00, 12:00, and 3:00, under clean and cloudy sky, during the summer of 2004/05, and winter of 2005. The red mesh presented differentiated transmittances at the PAR spectrum band which established an interesting material for acclimatization studies. Results show bigger reductions on the PAR spectrum band for the red mesh, regardless of time, solar radiation, or seasons, which agree with the results obtained by the spectral radiometer
\end{abstract}

Index terms: Musa sp., environment, seedling, shading.

'(Trabalho 018-08). Recebido em: 07-01-2008. Aceito para publicação em 12-08-2008.

${ }^{2}$ Eng. Agr., Dr. - Embrapa Transferência de Tecnologia, Caixa Postal 6062, CEP 13083-970, Campinas-SP. ciro@campinas.snt.embrapa.br ${ }^{3}$ Eng. Agric., Dr. Prof. Titular - FEAGRI/UNICAMP, Caixa Postal 6011, CEP 13083-970, Campinas-SP. pamleal@ feagri.unicamp.br

${ }^{4}$ Eng. Florestal., Pesq. Dr. - Embrapa Informática Agropecuária, Caixa Postal 6041, CEP 13083-970, Campinas-SP. giam@cnptia.embrapa.br 


\section{INTRODUÇÃO}

A utilização de mudas obtidas por micropropagação oferece vantagens, dentre as quais a redução do espaço e do tempo necessários à sua produção e à oferta de materiais livres de bactérias, fungos e nematóides prejudiciais às bananeiras. No entanto, imediatamente após a sua obtenção em laboratório, estas necessitam passar por um período de aclimatação, pois, na fase heterotrófica em que se encontram, não operam eficientemente a absorção de luz, água e nutrientes. A aclimatação deve ser feita então em casas de vegetação ou telado, onde as condições de umidade e luminosidade sejam favoráveis a um gradual endurecimento das tenras plântulas (Souza et al., 1997). No primeiro estágio da aclimatação, denominado pré-aclimatação ou berçário, as plântulas permanecem sob baixa intensidade luminosa e alta umidade relativa do ar até atingirem altura mínima de $10 \mathrm{~cm}$. O segundo estágio, ou aclimatação propriamente dita, inicia-se com a repicagem das mudas para bandejas, vasos ou sacolas, sob sombreamento ao redor de $50 \%$, temperatura ao redor de $28^{\circ} \mathrm{C}$, com mínimas a $18^{\circ} \mathrm{C}$ e máximas a $34^{\circ} \mathrm{C}$, e umidade relativa acima de 75\% (Souza et al., 1997; Hoffmann, 2002) até atingirem altura entre 25 e $30 \mathrm{~cm}$, momento em que são disponibilizadas ao mercado, sendo por ele consideradas pretensamente aclimatadas (Silva et al., 1999). Ambientes com 50 a $60 \%$ de sombreamento por 3 a 6 semanas e com sistema de atomização fina com água pura durante a primeira semana são necessários à primeira fase, reduzindo-se para 30 a 50\% na segunda fase (endurecimento), durante a aclimatação de mudas micropropagadas de bananeira cv. Grande Naine (Marie, 1995).

Dentre os fatores que podem concorrer para o insucesso na aclimatação de mudas micropropagadas, Hoffmann (2002) citase a perda excessiva de água como um dos principais, devido a pequenas quantidades de cera epicuticular e ao lento mecanismo de abertura e fechamento dos estômatos, sendo a redução gradativa da umidade relativa do ar, fator favorável na aclimatação. Cita, para tanto, o uso de ambientes com elevada umidade relativa do ar (acima de 90\%), através da utilização de nebulização intermitente ou de coberturas plásticas ou de vidro, com posterior redução gradativa da UR do ar, sombreamento, manutenção da sanidade do ambiente e das mudas, e uso de sistemas automatizados de aclimatação.

O resfriamento em casa de vegetação pode ser promovido por diferentes tipos de processos, tais como ventilação natural, ventilação forçada, resfriamento evaporativo do ar e refrigeração mecânica (Church et al., 1981). Os autores ainda destacam que o uso de resfriamento evaporativo do ar é o método de resfriamento mais extensivamente usado. Um desses sistemas é composto por um meio poroso ("pad") e um ventilador. A água é aplicada inteiramente no material do meio poroso e succionada ou propelida por um ou mais ventiladores localizados no lado oposto ou mesmo lado, respectivamente, da casa de vegetação.

Outro sistema muito utilizado de resfriamento evaporativo é o de nebulização, com vantagens na uniformidade de resfriamento, eliminando a necessidade de ventilação forçada (Abreu, 1999). Por outro lado, apresenta desvantagens de custo de instalação e uso de água de boa qualidade (Martins \& Gonzalez, 1995) e há que se ter cuidados quanto ao diâmetro máximo das gotas, que não devem exceder a $10 \mu \mathrm{m}$ a fim de se evitar o molhamento das plantas (Montero \& Antón, 1994). A eficiência do sistema de nebulização diminui com o aumento da umidade relativa no interior do ambiente protegido (Seeman, 1979).

O resfriamento evaporativo é um processo que reduz a temperatura de ar pela evaporação da água em contato com um fluxo de ar. Durante as horas mais quentes do dia, quando a temperatura de bulbo seco normalmente é maior, a diferença desta em relação à do bulbo úmido é aumentada. Assim, o maior potencial para resfriamento é obtido durante as horas mais quentes do dia, o que normalmente é mais desejado (Bucklin et al., 1993). Esse sistema de resfriamento evaporativo ou resfriamento adiabático não gera ganho ou perda de calor, pois a energia requerida para evaporar a água é suprida pelo ar, com conseqüentes umedecimento e redução da temperatura do ar (Abreu et al., 1999). O fator limitante para este sistema é a temperatura de bulbo úmido do ar externo.

A eficiência do sistema de resfriamento evaporativo depende da depressão psicrométrica, isto é, a diferença entre as temperaturas de bulbo seco e de bulbo úmido. Em regiões com depressão psicrométrica de 7 a $9^{\circ} \mathrm{C}$, foram observadas quedas de temperatura de $4 \mathrm{a} 7^{\circ} \mathrm{C}$, e para depressões maiores $\left(14\right.$ a $\left.17^{\circ} \mathrm{C}\right)$, as quedas variaram de 8 a $11^{\circ} \mathrm{C}$ (Witaker, 1979).

Montero et. al. (1990), estudando o efeito do sistema de resfriamento evaporativo por nebulização em ambiente protegido com filme multi EVA (etilenovinilacetato) e tela de sombreamento aluminizada com $45 \%$ de transmitância da radiação solar incidente, verificaram redução de $3^{\circ} \mathrm{C}$ na média quando comparado ao controle sem o sistema. Os autores verificaram ainda redução máxima de temperatura de $5^{\circ} \mathrm{C}$ em dias de sol, acompanhada de aumento da umidade relativa do ar, mantendo-se em $85 \%$.

Montero et al. (1985) destacam que umidades relativas muito altas, acima de $90 \%$, diminuem a taxa de transpiração das folhas, e umidades muito baixas, inferiores a 50\%, podem resultar em altos níveis de transpiração, causando estresse hídrico nas plantas. Os autores relatam que um sistema de resfriamento evaporativo pode ser capaz de conservar a umidade relativa da casa de vegetação entre $80-85 \%$.

O polietileno de baixa densidade (PEBD), material de cobertura plástica mais comumente empregado em ambientes sob cultivo protegido, apresenta transparência à radiação solar que varia, segundo Martin \& Robledo (1981), entre 70 a $95 \%$. Farias et al. (1993) encontraram valores de redução na transmissividade no intervalo de 11 às 13 horas, sendo que foi de $17 \%$, em média, ao longo do dia.

Essencialmente, todos os processos fisiológicos dependem de quantidade e qualidade de luz. A intensidade de radiação solar varia com a latitude, estação do ano, horário do dia, presença ou não de nuvens e transmitância da cobertura da estufa (Faria Junior \& Lima, 2000).

A faixa de espectro mais importante para os processos fotobiológicos situa-se do ultravioleta (200-400nm), espectro visível (400-700nm, região esta do espectro também denominada Radiação Fotossinteticamente Ativa - RFA) e infravermelho (740- 
1.600nm). De acordo com citações em Taiz \& Zeiger (2004), as faixas das regiões do espectro e respectivos efeitos sobre as plantas podem ser assim agrupadas: $1^{\text {a }}$ faixa: $>1.000 \mathrm{~nm}$ (infravermelho) - não causam danos às plantas e são por elas absorvidas, sendo aproveitadas sob a forma de calor sem que haja interferência com os processos biológicos; $2^{\mathrm{a}}$ faixa: entre 1.000 e 720nm - estes são os limites do espectro que exerce efeito no crescimento das plantas. A luz vermelha, no limite inferior da faixa, provoca um grande aumento na expressão de um gene que codifica uma enzima-chave na síntese da giberelina (Toyomatsu et al., 1998) que, por sua vez, pode promover o alongamento de internódios e o controle de floração; $3^{\mathrm{a}}$ faixa: entre 720 e $610 \mathrm{~nm}$ neste intervalo do espectro, ocorre absorção pela clorofila e carotenóides. Gera forte atividade fotossintética, apresentando em vários casos atividade fotoperiódica; $4^{\mathrm{a}}$ faixa: entre $610 \mathrm{e}$ 510nm - é uma faixa espectral de baixo efeito fotossintético e de fraca ação sobre a formação da planta. Corresponde à região verde do espectro; $5^{\text {a }}$ faixa: entre 510 e $400 \mathrm{~nm}$ - esta é essencialmente a faixa mais fortemente absorvida pelos pigmentos amarelos e pela clorofila. Corresponde ao azul-violeta do espectro e é também região de grande atividade fotossintética, exercendo ainda vigorosa ação na formação da planta; $6^{\mathrm{a}}$ faixa: entre 400 e 320nm (ultravioleta) - ocorre inibição de elongação celular, exercendo efeitos na formação das plantas (tornam-se mais baixas e as folhas mais grossas). A radiação ultravioleta A (UV-A), caracteriza-se por atuar como fotooxidante (Larcher, 2000); $7^{\text {a }}$ faixa: entre 320 e 280nm - é prejudicial à maioria das plantas. A radiação UV-B (280-314nm), além do efeito fotooxidante, causa lesões nas biomembranas (Larcher, 2000); 8 a faixa: $<280 \mathrm{~nm}$ - morte rápida das plantas.

O emprego de telas de sombreamento vem sendo indicado como uma das soluções de baixo custo, que, além de interceptarem a radiação solar incidente, contribuem para a redução da temperatura interna de abrigos para o cultivo protegido, porém é necessário que se estabeleçam níveis adequados de sombreamento, não prejudicial ao desenvolvimento e à produção vegetal (Faria Junior et al., 2000).

O uso de telas coloridas visa à combinação da proteção física da produção e filtro de luz, o que irá promover as respostas fisiológicas desejadas, tais como produtividade, qualidade e velocidade de maturação (Shahak et al., 2004). Os autores desenvolveram com a indústria de plástico uma série de telas plásticas de sombreamento, cada uma modificando especificamente o espectro da radiação filtrada nas regiões de UV, visível ou vermelho-distante e/ou aumentando a dispersão de radiação difusa e/ou afetando os componentes térmicos da região do infravermelho. Citaram ainda que estudos em diversas culturas sob várias telas coloridas, com mesmo índice de sombreamento de telas pretas (50 a 80\%, dependendo da cultura e da época) produziram respostas significativas. Comparadas com a tela preta, as telas vermelha e amarela estimularam, significativamente, o crescimento vegetativo, enquanto a azul causou nanismo.

Shahak et al. (2004) conduziram experimentos em pomares comerciais de maciera e pessegueiro usando telas coloridas (vermelha, amarela, azul, cinza e pérola) para reduzir luminosidade
(30\% de sombreamento). Resultados do primeiro ano mostram efeitos positivos no florescimento, padrão, tamanho, coloração e qualidade dos frutos, além de redução no estresse hídrico e queimaduras em frutos. Os autores afirmaram ser ainda muito cedo para delinear os mecanismos que envolvem as respostas, que podem estar relacionadas à qualidade da luz, à modificação do microclima gerado, ou ambas, abrindo novas perspectivas para implementar o desenvolvimento de pomares sob proteção.

O presente trabalho objetiva caracterizar os ambientes quanto aos impactos de temperatura e umidade relativa sob diferentes níveis de intensidade luminosa a que foram expostas mudas micropropagadas de bananeira cultivar Grande Naine, ao processo do segundo estágio da aclimatação.

\section{MATERIAL E MÉTODOS}

Os experimentos foram instalados em área experimental de coordenadas $22^{\circ} 48^{\prime} 57^{\prime \prime} \mathrm{S}, 47^{\circ} 03^{\prime} 33^{\prime \prime} \mathrm{W}$ e altitude de $640 \mathrm{~m}$ acima do nível do mar, tendo sido iniciados os de verão, em dezembro de 2004, e concluídos em fevereiro de 2005 . Os de inverno foram realizados no período de junho a agosto de 2005 .

Os ambientes experimentais foram compostos de 5 casas de vegetação, do tipo minitúnel, instaladas na orientação lesteoeste, com espaçamento de $2,0 \mathrm{~m}$ entre elas e cada uma com $2,0 \mathrm{~m}$ de largura (na altura das bancadas), 10,5m de comprimento e 2,0m de altura total. Elas foram cobertas, externamente, com filme PEBD de $100 \mu \mathrm{m}$ de espessura, aditivado contra raios ultravioleta (UV) e, internamente, em 4 delas, com diferentes malhas de sombreamento conforme descrição a seguir e, em uma, apenas com este filme:

A1 - Ambiente 1: malha Polysack ChromatiNet ${ }^{\circledR}$ vermelha 70 , com superfície de cobertura, segundo o fabricante, de 71 a $75 \%$;

A2 - Ambiente 2: malha Polysack plástica preta, com superfície de cobertura, segundo o fabricante, de 50 a 55\%;

A3 - Ambiente 3: malha Polysack ChromatiNet ${ }^{\circledR}$ vermelha 50 , com superfície de cobertura, segundo o fabricante, de 51 a $55 \%$;

A4 - Ambiente 4: Sem qualquer tipo de malha, contando apenas com a cobertura de filme PEBD de $100 \mu \mathrm{m}$;

A5 - Ambiente 5: malha Polysack ChromatiNet ${ }^{\circledR}$ vermelha 30 , com superfície de cobertura, segundo o fabricante, de 28 a $32 \%$.

Cada ambiente contou com bancada de $6,24 \mathrm{~m}$ de comprimento, 2,0m de largura, $0,8 \mathrm{~m}$ de altura em relação ao solo, e $2 \mathrm{~cm}$ de espessura, sendo dispostas sobre cada uma delas 24 bandejas ( 3 para cada bloco) localizadas ao centro da estrutura e com limites a 2,18m de suas extremidades leste e oeste, distância suficiente para se evitar a incidência direta da luz solar (Leal, 2003). Cada bandeja continha 24 mudas pré-aclimatadas de 10 a $12 \mathrm{~cm}$ de altura, perfazendo um total de 576 mudas, sendo 192 úteis.

Ao término dos experimentos com plantas, durante os meses de abril/2005 e maio/2005, para a caracterização da transmitância, refletância e absortância de cada uma das coberturas dos ambientes, foram conduzidas análises espectro- 
radiométricas a partir de amostras das diversas telas e filmes plásticos utilizados, que compuseram cada um dos diferentes conjuntos de sombreamento. Para tanto, foram coletadas 5 amostras de cada tela e filme utilizados, sendo constituídas de discos com $5 \mathrm{~cm}$ de diâmetro tomados ao acaso, ao longo de cada um dos ambientes, os quais, depois de identificados, foram encaminhados para o CEPAGRI (Centro de Pesquisas Meteorológicas e Climáticas Aplicadas à Agricultura) da UNICAMP para a consecução das análises, utilizando-se de espectro radiômetro LI-COR mod. LI-1800 com o acessório LI180012 S ("External Integrating Sphere"). Assim, as análises foram executadas, tomando-se 5 repetições das amostras conjuntas (tela e filme), exceto para o A4, constituído apenas do filme.

Para a manutenção da temperatura interna do ar dentro da faixa recomendada, foi instalado sistema de resfriamento "meio poroso-ventilador", que contou com cinco resfriadores evaporativos, marca Ecobrisa, modelo EB 50, um para cada ambiente, disposto na extremidade leste de cada um, regulados para acionamento a $28^{\circ} \mathrm{C}$ e parada aos $25^{\circ} \mathrm{C}$.

Visando a manter a umidade relativa do ar nos níveis desejados, foi instalado sistema de nebulização composto de conjunto motobomba (KSB, mod. P1000, de $1 \mathrm{CV}$ ), ligado por tubulação de PVC ( $25 \mathrm{~mm}$ de diâmetro) a 5 conjuntos (um para cada ambiente), compostos de 5 nebulizadores cada (modelo Fogger de vazão de $7 \mathrm{~L} / \mathrm{h}$ sob pressão de $4,0 \mathrm{kgf} / \mathrm{cm}^{2}$ ). O sistema era acionado durante o dia (das $8 \mathrm{~h}$ às $18 \mathrm{~h}$ ) por umidostato e temporizador intermintente ( $6 \mathrm{~s}$ a cada $40 \mathrm{~s}$ ) sempre que aumidade relativa do ar interno aos ambientes fosse inferior a $75 \%$.

Os dados de temperatura e de umidade relativa do ar foram obtidos por meio de psicrômetros aspirados, instalados na porção inicial, intermediária e final de cada ambiente. Foram então construídas, especificamente para este fim, 3 unidades para cada ambiente, além de mais uma para avaliação do ar externo.

Cada psicrômetro foi construído com tecnologia e materiais relativamente simples, utilizando-se de tubo de PVC de $100 \mathrm{~mm}$, com $40 \mathrm{~cm}$ de comprimento, sendo internamente fixado à sua parede outro tubo de menor diâmetro $(50 \mathrm{~mm})$, de apenas $20 \mathrm{~cm}$ de comprimento, fechado na extremidade inferior para função de reservatório de água. Nesse tubo menor, foi fixado um cordão de algodão de $0,5 \mathrm{~cm}$ de diâmetro por $20 \mathrm{~cm}$ de comprimento, tendo uma das extremidades imersa em água destilada presente no reservatório, reposta diariamente até o seu limite superior. A outra extremidade do cordão foi mantida fora do reservatório, com o objetivo de, por capilaridade, manter-se constantemente umedecida. Dentro do tubo maior, foram fixados 2 termopares do Tipo T, sendo 1 fixado na extremidade externa do cordão, para tomadas de temperatura de bulbo úmido, e outro suspenso no centro do tubo, para tomadas de temperatura de bulbo seco. $\mathrm{Na}$ extremidade superior do tubo maior, foi fixado um microventilador, modelo $4 \mathrm{x} 4 \mathrm{DC} 12 \mathrm{~V}$, com o objetivo do fornecimento de fluxo constante de ar para proporcionar evaporação da água no cordão, possibilitando, assim, tomadas corretas de temperatura de bulbo úmido. Todo o conjunto foi revestido externamente por filme refletivo para eliminar a influência de aquecimento pela radiação solar incidente.

Para o cálculo da umidade relativa do ar, utilizaram-se as temperaturas de bulbo seco e bulbo úmido, que, aplicadas ao software GRAPSI 6.0 (Melo et al., 2004), revelaram dados da umidade relativa do ar.

Os dados de temperatura e de umidade relativa do ar foram submetidos a ANOVA, utilizando-se do pacote estatístico Statgraphics v.4.1, e as médias diárias entre cada ambiente, comparadas pelo teste de Tukey, a 5\% de probabilidade.

No interior de cada ambiente, foram coletados dados de irradiâncias de RFA e global por meio de sensores LI-COR, com detectores fotovoltaicos de silício de alta estabilidade. Para tanto, foram efetuadas medidas por 10 minutos, com partição de 30 segundos, por volta das $9 \mathrm{~h}, 12 \mathrm{~h}$ e $15 \mathrm{~h}$, em 2 situações distintas de insolação: céu claro e céu encoberto e, respeitada cada situação, em 3 dias escolhidos ao acaso ao longo da execução dos experimentos. As tomadas foram feitas utilizando-se de um conjunto composto de 2 sensores LI-COR instalados sobre a bancada e na porção mediana de cada ambiente (um, sensor Quantum LI-190SA, para medir a RFA na faixa visível de 400 a 700nm, e o outro, sensor piranômetro LI-200SZ, para medir a radiação solar global na faixa de 400 a $1.100 \mathrm{~nm}$ ) conectados à Data-Logger LI-COR, modelo LI-1.400. Para comparações com o meio externo, outro conjunto idêntico foi instalado simultaneamente do lado de fora de cada ambiente. Dessa forma, foi possível estabelecer relações de redução da luminosidade proporcionada pelo tipo de cobertura de cada ambiente.

\section{RESULTADOS E DISCUSSÃO}

A Figura 1 apresenta os valores pontuais de interceptação da luz ao longo do espectro na faixa da RFA, obtido por espectrorradiometria com resolução espectral de $2 \mathrm{~nm}$, proporcionados pelos materiais utilizados nos diferentes ambientes.

A Tabela 1 apresenta o comparativo entre os dados médios, na faixa da RFA, obtidos por meio do espectrorradiômetro a partir de amostras dos materiais novos e aqueles apresentados pelo fabricante. Para as malhas, os valores médios obtidos encontram-se muito próximos àqueles fornecidos pelo fabricante, enquanto para o filme, o valor médio obtido encontra-se dentro da faixa (Martin \& Robledo, 1981).

A Figura 2 apresenta as características de transmitância e reflectância de cada um dos conjuntos, malha e filme, exceto para o ambiente 4 (A4), constituído apenas do filme.

As relações de redução da luminosidade proporcionada pelo tipo de cobertura de cada ambiente, baseadas na coleta de dados instantâneos de irradiâncias dentro e fora de estufas, simultaneamente, encontram referências em trabalho de Frisina et al., 2000. Tais relações estão ilustradas na Figura 3, que mostra que, dentro da região da RFA, os percentuais médios de redução da transmitância proporcionados pelas malhas vermelhas (ambientes A1, A3 e A5) são maiores do que aqueles na região da radiação global, o que está de acordo com o que se pode observar na Figura 2, que apresenta transmitâncias obtidas por espectrorradiometria.

Diferentemente, para o ambiente A2, de malha preta, esse diferencial não é observado na Figura 3, fato também verificado 
na resposta linear de transmitância da Figura 2.

Na comparação entre os ambientes A2 (de malha preta) e A3 (de malha vermelha), ambos de classificação comercial como de $50 \%$ de sombreamento, verifica-se que a malha vermelha atua como filtro até a região dos $570 \mathrm{~nm}$, transmitindo e refletindo, a partir dessa faixa, cerca de $20 \%$ mais radiação que a malha preta.

Os dados médios de temperatura e de umidade relativa coletados durante a realização dos experimentos de verão (de 15-12-04 a 17-02-05) e de inverno (de 22-06-05 a 24-08-05) encontram-se nas Figuras 4 e 5. Eles revelam que o controle ambiental proporcionado apresentou resultados satisfatórios do ponto de vista de exigências da planta (Souza et al., 1997; Hoffmann, 2002), embora tenham sido encontradas diferenças significativas entre os ambientes (Tabela 2) quando comparados pelas médias diárias.

Considerando-se que os fatores que influenciam na temperatura do ar no interior dos ambientes, tais como tamanho e volume de cada um, ângulo de incidência da radiação solar, filme de cobertura plástica, re-irradiação pelos objetos em seu interior (Seeman, 1979 e Farias et al., 1993) eram comuns e que os sistemas de resfriamento e nebulização ofereciam igualdade de condições, as diferenças encontradas devem ser creditadas às malhas de sombreamento com diferentes características de transmitância e reflectância e conseqüente condução de calor.

Os ambientes menos sombreados (A4 e A5) apresentaram maiores temperaturas médias internas. Por outro lado, o ambiente A1, mais sombreado, apresentou menores temperaturas, tanto no verão quanto no inverno, enquanto os ambientes A2 e A3, de sombreamento intermediário, apresentaram temperaturas também intermediárias.

Quanto à umidade relativa no interior dos ambientes, o ambiente A1 apresentou sempre valores mais elevados, devido às suas menores temperaturas, o que permite menores valores de pressão de saturação de vapor de água. Quanto aos demais, tanto para verão como para inverno, os valores médios de umidade relativa estiveram dentro dos limites exigidos pela planta. Eles revelam que, no inverno, pelas características da sazonalidade (umidades relativas mais baixas) e pelo fato de o sistema de nebulização operar isoladamente, sem o auxílio do sistema de resfriamento evaporativo, os valores estiveram sempre próximos ao limite inferior estabelecido pelo umidostato.

TABELA 1- Características das malhas e filme utilizados.

\begin{tabular}{lcc}
\hline Material & Superfície de cobertura $(\%)(*)$ & Interceptação da radiação $\left(^{* *}\right)$ \\
\hline ChromatiNet $^{\mathbb{B}}$ vermelha 30 & $28-32$ & 29,73 \\
ChromatiNet $^{\mathbb{B}}$ vermelha 50 & $51-55$ & 50,73 \\
ChromatiNet $^{\mathbb{Q}}$ vermelha 70 & $71-75$ & 69,92 \\
Preta 50 & $50-55$ & 57,77 \\
Filme PEBD 100 m & Transparente & 12,74 \\
\hline
\end{tabular}

(*) especificações do fabricante. (**) Obtida por espectrorradiometria (LI-1800) com esfera externa (LI-1800 12S).

TABELA 2- Médias diárias de temperatura (bulbo seco) e de umidade relativa no interior dos ambientes no período de 15-12-2004 a 1702-2005 (verão) e de 22-06-2005 a 24-08-2005 (inverno) e respectivas pressões* parcial (pv) e de saturação (ps) de vapor de água no ar.

\begin{tabular}{ccccccccc}
\hline AMBIENTE & \multicolumn{9}{c}{ VER $\tilde{O}$} \\
& $\mathrm{~T}^{\mathrm{o}}\left({ }^{\circ} \mathrm{C}\right)$ & $\mathrm{UR}(\%)$ & $\mathrm{pv}(\mathrm{kPa})$ & $\mathrm{ps}(\mathrm{kPa})$ & $\mathrm{T}^{\mathrm{o}}\left({ }^{\mathrm{o}} \mathrm{C}\right)$ & $\mathrm{UR}(\%)$ & $\mathrm{pv}(\mathrm{kPa})$ & $\mathrm{ps}(\mathrm{kPa})$ \\
\hline 1 & $24,6^{\mathrm{d}}$ & $88,0^{\mathrm{a}}$ & 2,731 & 3,102 & $19,8^{\mathrm{d}}$ & $79,4^{\mathrm{a}}$ & 1,830 & 2,306 \\
2 & $25,9^{\mathrm{c}}$ & $84,9^{\mathrm{bc}}$ & 2,845 & 3,349 & $21,7^{\mathrm{b}}$ & $73,4^{\mathrm{c}}$ & 1,908 & 2,598 \\
3 & $26,0^{\mathrm{c}}$ & $87,5^{\mathrm{a}}$ & 2,938 & 3,357 & $21,1^{\mathrm{c}}$ & $75,4^{\mathrm{b}}$ & 1,892 & 2,509 \\
4 & $26,9^{\mathrm{a}}$ & $85,9^{\mathrm{b}}$ & 3,053 & 3,551 & $22,1^{\mathrm{a}}$ & $72,7^{\mathrm{c}}$ & 1,933 & 2,661 \\
5 & $26,6^{\mathrm{b}}$ & $84,3^{\mathrm{c}}$ & 2,941 & 3,488 & $22,1^{\mathrm{a}}$ & $75,2^{\mathrm{b}}$ & 2,003 & 2,664 \\
\hline $\mathrm{CV}(\%)$ & 1,27 & 2,54 & \multicolumn{7}{c}{1,61} & 4,68 \\
\hline
\end{tabular}

Médias seguidas por letras iguais não diferem entre si, pelo teste de Tukey, a 5\% de probabilidade.

* Calculadas pelo programa computacional Psychros v1.4 (Mendes, 1997).

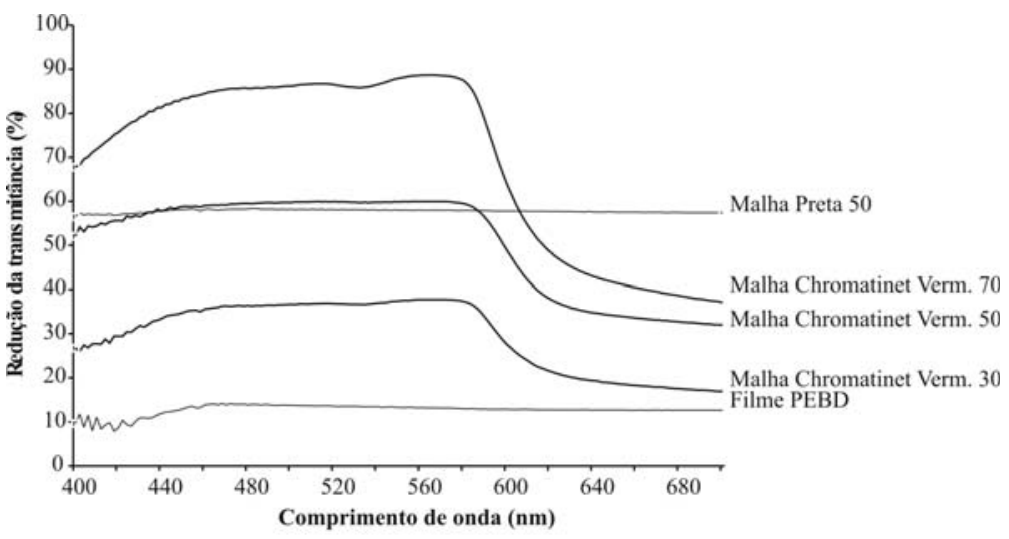

FIGURA 1 - Sombreamento proporcionado pelos materiais utilizados nos diferentes ambientes, obtido por espectro-radiometria na faixa da RFA. 

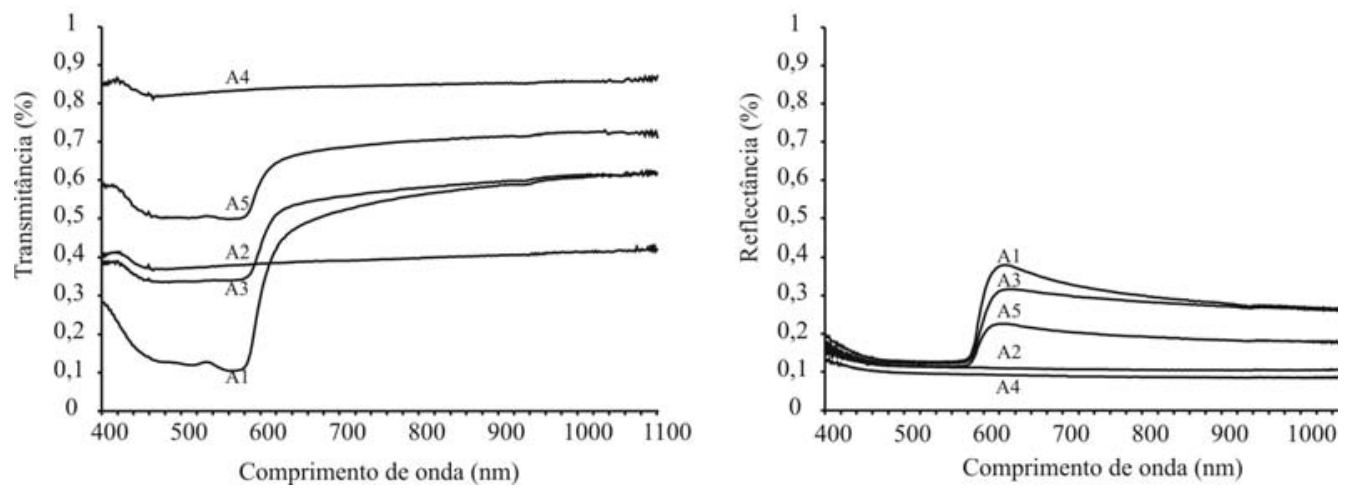

FIGURA 2 - Transmitância e reflectância obtidas por espectro-radiometria em cada um dos ambientes.
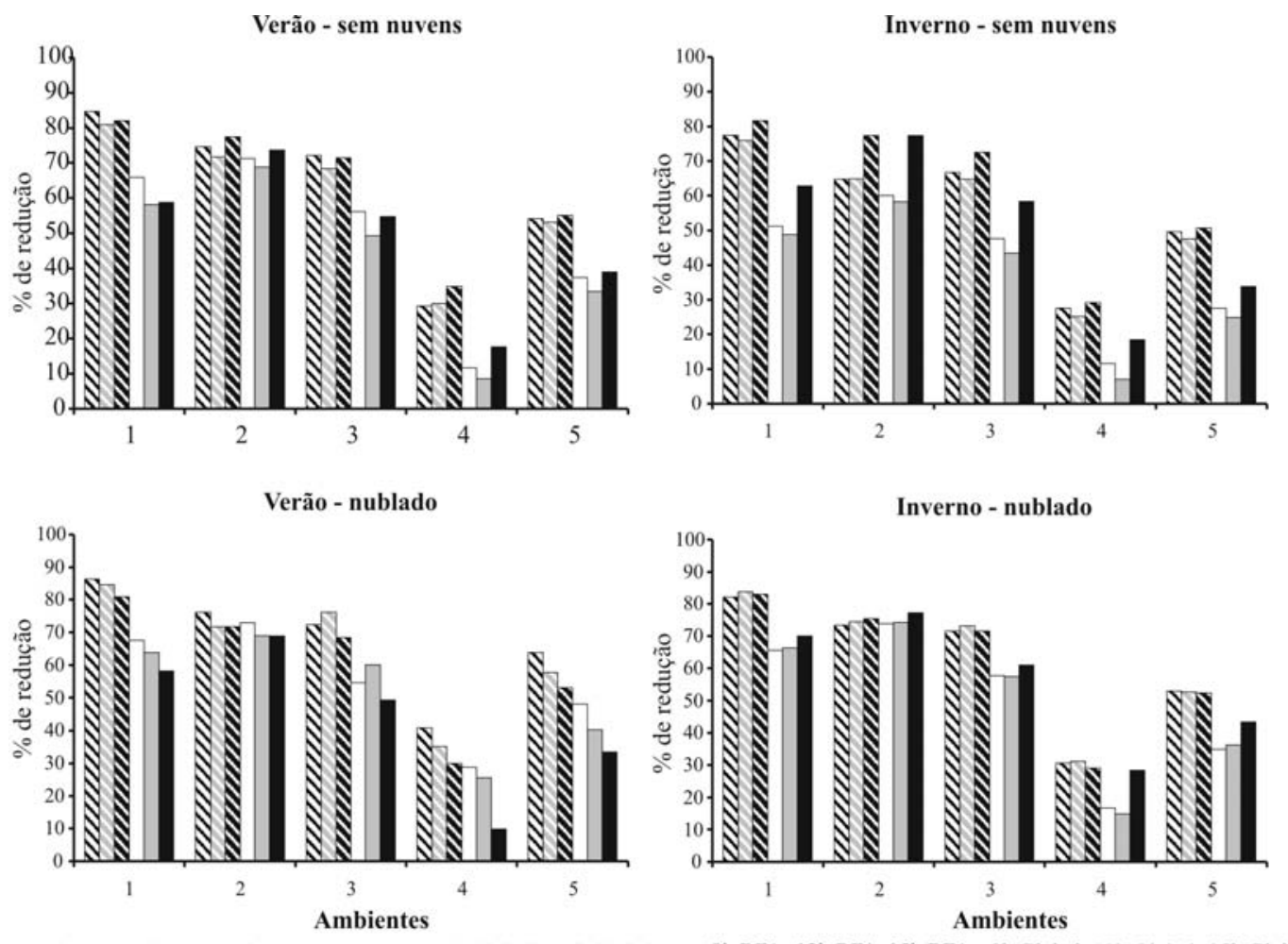

s9h RFA घ12h RFAs15h RFA $\square 9 \mathrm{~h}$ Globalø12h Global $15 \mathrm{~h}$ Global

s9h RFA घ12h RFAsl 5h RFA $\square$ 9h Globala12h Globalul5h Global

FIGURA 3 - Redução média da radiação Global e RFA, medidas por meio de sensores fotovoltaicos em cada ambiente, comparada ao meio externo em condições de inexistência de nuvens e de céu nublado, durante os experimentos de verão e inverno em casas de vegetação.
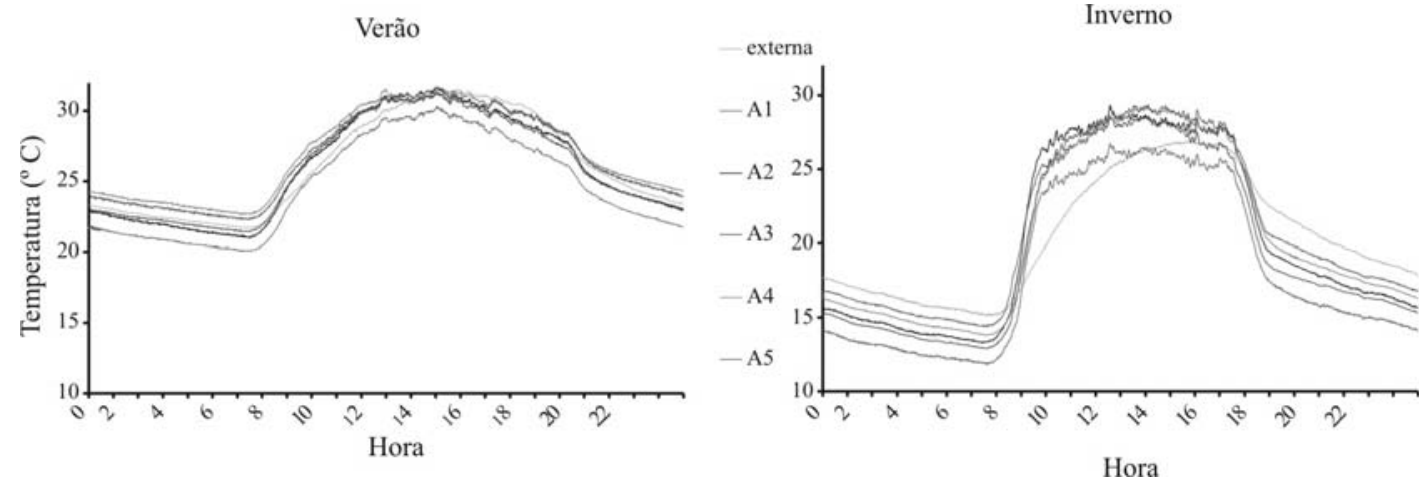

FIGURA 4 - Médias de temperatura em cada ambiente ao longo do dia, durante 9 semanas de aclimatação no verão (de 15-12-04 a 1702-05) e no inverno (de 22-06-05 a 24-08-05). 

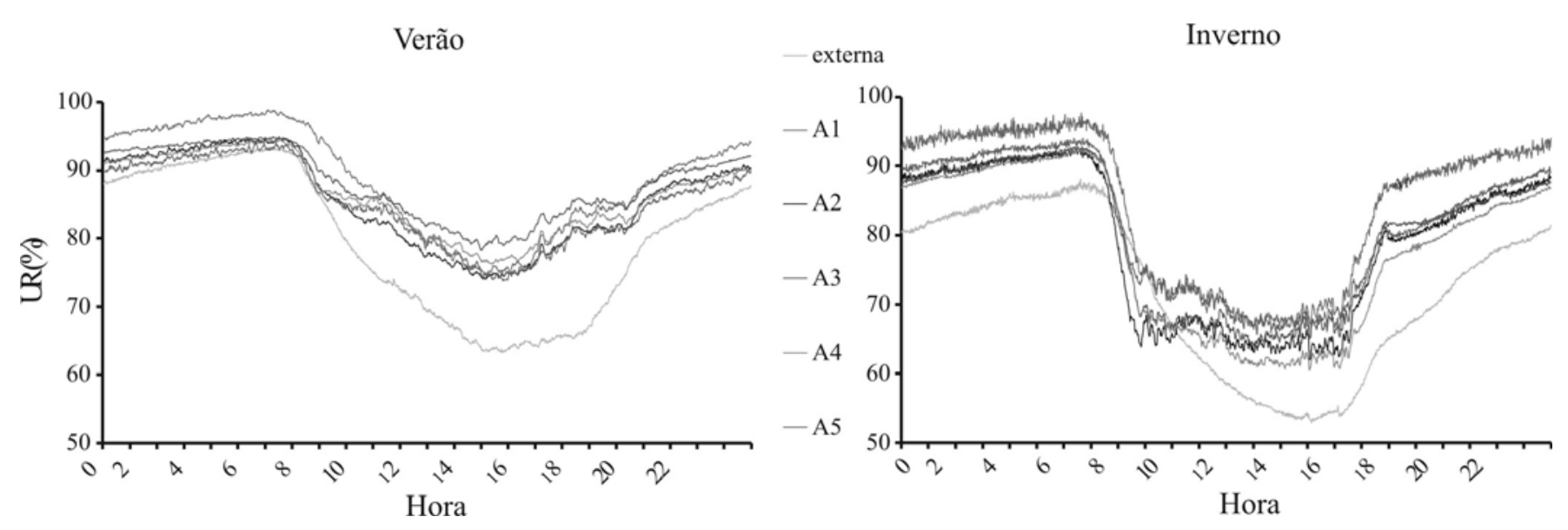

FIGURA 5 - Médias de umidade relativa em cada ambiente ao longo do dia, durante 9 semanas de aclimatação no verão (de 15-12-04 a 17-02-05) e no inverno (de 22-06-05 a 24-08-05).

\section{CONCLUSÕES}

Nas condições em que foram conduzidos os trabalhos:

1-As malhas vermelhas utilizadas apresentaram transmitâncias diferenciadas ao longo do espectro da radiação fotossinteticamente ativa, com picos de redução ao redor dos 570nm, constituindo-se assim em interessantes materiais nos estudos sobre aclimatação. Resultados comparativos com o meio externo, por meio de sensores fotovoltaicos, mostraram maiores reduções na faixa RFA para as telas vermelhas, independentemente do horário, insolação e estação do ano, concordantes com aqueles obtidos por espectrorradiômetro.

2-Considerando os sistemas de resfriamento evaporativo e de nebulização intermitente utilizados, iguais em todos os ambientes, o nível de sombreamento oferecido é inversamente proporcional à temperatura e diretamente proporcional à umidade relativa interna do ar. Embora com comportamentos diferentes quanto à temperatura e umidade, todos os ambientes estudados ofereceram as condições requeridas pelas plantas de bananeira, sob o $2^{\circ}$ estágio de aclimatação.

\section{REFERÊNCIAS}

ABREU, P.G. de; ABREU, V.M.N.; MAZZUCO, H. Uso do resfriamento evaporativo (adiabático) na criação de frangos de corte. Concórdia: EMBRAPA, CNPSA, 1999. 51p. (Documentos, 59).

BUCKLIN, R.A.; LEARY,J.D.; MCCONNELL, D.B.; WILKERSON, E.G. Fan and pad greenhouse evaporative cooling systems. Gainsville: Department of Agricultural and Biological Engineering, Florida Cooperative Extension Service, Institute of Food and Agricultural Sciences, University of Florida. 2003 (Circular, 1135). Disponível em: <http://edis.ifas.ufl.edu/AE069>. Acesso em: 16 abr. 2004.
CHURCH, G. A.; WATERS, W. F.; LAZIN, M. B. Application of ground water to greenhouse cooling systems. Chicago: American Society of Agricultural Engineers, 1981. p.15-18.

FARIA JUNIOR, M. J. A.; LIMA, A. M. Uso de Sombreamento em Estufa Coberta com Polietileno e com ventilação natural: efeitos sobre variáveis climáticas. In: CONGRESSO BRASILEIRO DE ENGENHARIA AGRÍCOLA, 29., 2000, Fortaleza. Anais... 2000.

FARIAS, J.R.B.; BERGAMASCHI, H.; MARTINS, S.R.; BERLATO, M.A.; OLIVEIRA, A.C.B. Alterações na temperatura e umidade do ar provocadas pelo uso de estufa plástica. Revista Brasileira de Agrometeorologia, Campinas, v.1, n.1, p.51-62, 1993.

FRISINA, V.A.; ESCOBEDO, J.F.; GOMES, E.N. Estimativa da radiação fotossinteticamente ativa (PAR) em estufa de polietileno. In: ENCONTRO DE ENERGIA NO MEIO RURAL, 3., 2000, Campinas. Disponível em:

< h t t p : / / w w w.proce ed ing s. s c i e lo.br/ scielo.php?script=sci_arttex \&pid=MSC000000002200000 0200056\&lng=en\&nrm=abn>. Acesso em: 18 maio 2006.

HOFFMANN, A. Aclimatação de mudas produzidas in vitro e in vivo. Informe Agropecuário, Belo Horizonte, v. 23, n. 216, p. 2124,2002 .

LARCHER, W. Ecofisiologia vegetal. São Carlos: Rima, 2000.531p.

LEAL, P.A.M. Radiação solar: curso estudo dirigido em construções rurais e ambiência. Campinas: Faculdade de Engenharia Agrícola, 2003. 36 f. Notas de aula.

MARIE, P. L'acclimatation des vitroplants de bananiers de Grandee Naine. Montepellier: CIRAD-FLHOR, 1995.21 p. 
MARTIN, E.C.; ROBLEDO, L.V. Aplicación de los plásticos en la agricultura. Madrid: Mund-Pressa, 1981.55p.

MARTINS, S.R.; GONZALEZ, J.F. Avaliação do resfriamento em estufa plástica mediante sistema de ventilação e nebulização. Revista Brasileira de Agrometeorologia, Campinas, v. 3, p. 13$18,1995$.

MELO, E.C.; LOPES, D.C.; CORRÊA, P.C. GRAPSI - Programa computacional para o cálculo das propriedades psicrométricas do ar. Engenharia na Agricultura, Viçosa, v.12, n.2, p.154-162, 2004. Disponível em: <http://www.ufv.br/dea/reveng/arquivos/ vol12/v12n2p154-162.pdf>. Acesso em: 29 nov. 2005.

MENDES, N. Programa computacional para cálculo de umidade relativa ou temperatura de bulbo úmido. Florianópolis: Laboratório de Eficiência Energética em Edificações. Universidade Federal de Santa Catarina, 1997. Disponível em: <http://www.labeee.ufsc.br/software/psychros.html>. Acesso em: 04 jul. 2006.

MONTERO, J.I.; CASTILLA, N.; GUTIERREZ de RAVÉ, E.; BRETONES, F. Climate under plastic in the Almeria. Acta Horticulturae, Wageningen, n.170, p.227-234, 1985.

MONTERO, J.I.; ANTÓN, A.; BIEL, C.; FRANQUET, A. Cooling of greenhouse with compressed air fogging nozzles. Acta Horticulturae, Wageningen, n.281, p.199-209, 1990.

MONTERO, J.I.; ANTÓN, A. Greenhouse cooling during warm periods. Acta Horticulturae, Wageningen, v. 357, p. 49-61, 1994.
SEEMAN, J. Greenhouse climate. In: Seeman, J.; Chirkov, Y.I.; Lomas, J.; Primault, B. Agrometeorology. Berlin : Springer-Verlag Berlin, 1979. p.165-178.

SHAHAK, Y.; GUSSAKOVSKY, E. E.; COHEN, Y.; LURIE, S.; STERN, R.; KFIR, S.; NAOR, A.; ATZMON, I.; DORON, I. e GREENBLAT-AVRON, Y. ColorNets: ANew Approach for Light Manipulation in Fruit Trees. Acta Horticulturae, Wageningen, v.636, p. 609-616, 2004.

SILVA, D.S.; BOSISIO, A.; BOSCAROL, B.; BELTZER, A.; AMSLER, G. P. Aclimatação de mudas de bananeira (Musa spp.) "Prata"(AAB) em diferentes substratos. Revista Ceres, Viçosa, v. 46, n. 267, p. 543-554, 1999.

SOUZA, A. S.; DANTAS, J. L. L.; SOUZA, F. V. D.; CORDEIRO, Z. J. M.; SILVA NETO, S. P. Propagação. In: ALVES, E. J. (Org.). A cultura da banana: aspectos técnicos, socioeconômicos e agroindustriais. Brasília: EMBRAPA-SPI, 1997. p.151-195.

TAIZ, L.; ZEIGER, E. Fisiologia vegetal. Porto Alegre: Artmed, 2004. 719p.

TOYOMATSU, T.;KAWAIDE,H.; INOUE,Y.; KAMIYA, Y. Phytochrome regulates gibberellin biosynthesis during germination of photoblastic lecttuce seeds. Plant Physiology, Stuttgart, v. 118, p.1517-23, 1998.

WHITAKER, J.H. Agricultural building and structure. Heston: Heston Publishing Company, 1979. 289 p. 